\title{
Molecular epidemiology of HCV among health care workers of Khyber Pakhtunkhwa
}

\author{
Sanaullah Khan ${ }^{1 *}$, Sobia Attaullah ${ }^{2 \dagger}$, Sultan Ayaz ${ }^{1}$, Shahid Niaz Khan ${ }^{1}$, Sumaira Shams ${ }^{1}$, ljaz Ali $^{3}$, Muhammad Bilal ${ }^{4}$, \\ Sami Siraj ${ }^{5}$
}

\begin{abstract}
Background: Studies of the molecular epidemiology and risk factors for hepatitis C virus (HCV) in health care workers (HCWs) of Peshawar, Khyber Pakhtunkhwa region are scarce. Lack of awareness about the transmission of $\mathrm{HCV}$ and regular blood screening is contributing a great deal towards the spread of hepatitis C. This study is an attempt to investigate the prevalence of HCV and its possible association with both occupational and nonoccupational risk factors among the HCWs of Peshawar.

Results: Blood samples of $824 \mathrm{HCWs}$, aged between 20-59 years were analysed for anti-HCV antibodies, HCV RNA and HCV genotypes by Immunochromatographic tests and PCR. All relevant information was obtained from the HCWs with the help of a questionnaire. The study revealed that $4.13 \%$ of the HCWs were positive for HCV antibodies, while HCV RNA was detected in $2.79 \%$ of the individuals. The most predominant HCV genotype was 3a and 2a.
\end{abstract}

Conclusion: A program for education about occupational risk factors and regular blood screening must be implemented in all healthcare setups of Khyber Pakhtunkhwa province in order to help reduce the burden of HCV infection.

\section{Background}

Acquisition of blood borne pathogens is a potential occupational health hazard for health care workers (HCWs) across the world [1]. Transmissions of over 20 different pathogens have been reported in HCWs because of occupational exposure [2,3]. Despite of continuous progressive preventive measures and employment of modern medical apparatus, HCWs performing exposures prone procedures run a risk for a vast array of blood born pathogen like Hepatitis C Virus (HCV) $[4,5]$. HCV, compared to a "viral time bomb, is leading hepatotropic virus and predominant cause of severe pathological consequences like acute hepatitis, chronic liver diseases and hepatocellular carcinoma [6,7].

Currently, approximately 10 million people in Pakistan are suffering from $\mathrm{HCV}$, covering $6 \%$ of the overall population and it falls in the intermediate endemic zone [8]. Such a high prevalence of HCV has earlier been

\footnotetext{
* Correspondence: sanaullahkust@gmail.com

† Contributed equally

'Molecular Parasitology and Virology Laboratory, Department of Zoology,

Kohat University Kohat Khyber Pakhtunkhwa, Pakistan

Full list of author information is available at the end of the article
}

attributed to the absence of good preventive measures, inadequate funding for health care resources, tremendous increase in work load, inadequate provision of barrier devices for the HCWs. Moreover, high frequency of $\mathrm{HCV}$ among the general population put them at a high risk of acquiring HCV infection [5,9]. Care of HCWs is utmost important because healthy and fearless health worker can provide better services to suffering humanity [10]. A small number of studies are available on the epidemiology of $\mathrm{HCV}$ in HCWs from different regions of Pakistan. However in Khyber Pakhtunkhwa, the molecular epidemiology of HCV and its associated occupational risk factors have never been investigated before. This study was designed to know the prevalence of antiHCV, HCV RNA, HCV genotypes and occupational risk factors for HCV infection among the HCWs in major hospitals of Peshawar, Khyber Pakhtunkhwa Pakistan.

\section{Methods \\ Setting}

HCWs from three, major public sector, tertiary and high complexity care hospitals of Peshawar, including Khyber Teaching Hospital, Lady Reading Hospital and Hayatabad
C Biomed Central

() 2011 Khan et al; licensee BioMed Central Ltd. This is an Open Access article distributed under the terms of the Creative Commons Attribution License (http://creativecommons.org/licenses/by/2.0), which permits unrestricted use, distribution, and reproduction in any medium, provided the original work is properly cited. 
Medical Complex Hospital were sources of blood samples for this study.

\section{Study Population}

This study was conducted with the approval of the Medical Superintendents of source hospitals and the ethics committee of Kohat University of Science and Technology (KUST) Kohat Pakistan. The HCWs working for the last six months at the source hospitals were divided into five groups. i- doctors (surgeons, physicians and dentists); ii- nursing staff (staff nurses, professional nurses and midwifery staff); iii- specialized technicians (X-rays, anesthesia and laboratory personals; serologists, microbiologists, hematologists, pathologists, biochemists, biomedical assistants, physiotherapists and occupational therapists), iv- Assistants (radiology, operational services, helpers, attendants) and general services (laboratory, cleaning, laundry, blood bank, pharmacists, security guard housekeeping staff, dispensers, security guards, catering staff and drivers of ambulance) and v- administrative staff.

\section{Study procedure}

Self assessment questionnaire was pre-designed according to the object of the study which included, i) Personal data; gender, marital status, age, and education, ii) Professional data; job category, working department and duration of the job, iii) History of the risk of viral hepatitis infection including blood transfusion, intravenous drug usage, hospitalization, surgery and dental treatment, vi) History of HCV including history of jaundice, history of HCV in the family and v) History of frequency of occupational exposure.

\section{Laboratory test}

Serum was separated after blood collection, labeled and stored frozen at $-20^{\circ} \mathrm{C}$ at the laboratory of Molecular Parasitology and Virology, Department of Zoology, KUST Kohat. All the samples were screened by immunochromatography tests (Acurate Diagnostics, USA). HCV RNA was isolated with GF-1 RNA extraction Kit (Vivantus, USA), reverse transcribed with $200 \mathrm{U}$ of Moloney muriene leukemia virus reverse transcriptase (Fermentas Inc. USA) and 5'UTR of HCV was amplified with nested primers. Positive samples for HCV RNA were genotyped as mentioned elsewhere [11].

\section{Statistical analysis}

Results were statistically analyzed by using Chi square (with Yates's test) or Fisher's exact test. The disease "exposure" association was determined by estimating the Odd ratio (OR) and 95\% Confidence intervals (CI) in the case of significant association found. In this study $P$ value of less than 0.05 was adopted as statistically significant.

\section{Results}

Among the 824 participated HCWs, 200 (24.2\%) were doctors, 240 (29.1\%) were nursing staff, 240 (29.1\%) were technicians, 114 (13.8\%) were general and assistant staff and 30 (3.6\%) were administrative staff. The duration of their employment ranged from 6 months to 29 years (mean $14.4 \pm 3.21$ years) (Table 1$)$. Among them, $493(59.8 \%)$ were male and $331(40.2 \%)$ were female, 677 (82.2\%) were married and 147 (17.8\%) were unmarried. Overall mean age was $33.8 \pm 8.2$ years and ranged from 20 to 59 years. $69.4 \%$ (572) and 30.6\% (252) HCWs fell in undergraduate and graduate categories, respectively. History of blood transfusion was recorded in $24 \mathrm{HCWs}(2.91 \%)$, dental treatment in $100 \mathrm{HCWs}$ (12.2\%), intravenous drug injections in $1(0.12 \%)$, hospitalization in $98(11.9 \%)$, surgery in $31(3.8 \%)$ while none had a positive history in their families. History of $\mathrm{HCV}$ positivity was recorded in $6(0.72 \%) \mathrm{HCWs}$.

$4.1 \%$ (34 out of 824 ) of HCWs had antibodies against $\mathrm{HCV}$, of which 21 (61.8\%) were male and 13 (38.2\%) were female while 25 (73.5\%) were married and 9 (26.4\%) were unmarried. 32 (94.1\%) positive HCWs belonged to the undergraduate category while only $2(5.9 \%)$ from the graduate category (Table 2). Of these positive cases, 18 $(52.9 \%)$ had history of dental treatment, 4 (11.8\%) had been transfused, $4(11.6 \%)$ had surgery in the past, 4 (11.8\%) had a history of hospitalization, 3 (8.82.5) had jaundice and one of them were intravenous drug users (Table 3). HCV RNA was detected in 23 (2.79\%) HCWs. The most predominant HCV genotype was 3a (73.91), followed by $3 \mathrm{~b}(13.04 \%)$, 1a (4.34\%), mixed infection (4.34\%) and unidentified genotyping (4.34\%). With respect to the professional categories, $44.1 \%$ (15 out of 240 ) of nurses, $32.3 \%$ (11 out of 240 ) of technicians, $14.7 \%$ (5 out of 114) of assistant and general staff, $8.8 \%$ (3 out of 200) of doctors and none of administrative staff were infected with HCV. In this study occupational accidents most frequently occurred in HCWs by work

Table 1 HCWs distribution (\%) according to age, gender and occupational categories

\begin{tabular}{lllllll}
\hline Gender & \multicolumn{3}{c}{ Age (in years) } & Total \\
\cline { 2 - 6 } & $\mathbf{2 0 - 2 9}$ & $\mathbf{3 0 - 3 9}$ & $\mathbf{4 0 - 4 9}$ & $\mathbf{5 0 - 5 9}$ & \\
\hline Female & 89 & 169 & 62 & 11 & $\mathbf{3 3 1}$ \\
\hline Male & 106 & 171 & 178 & 38 & $\mathbf{4 9 3}$ \\
\hline Categories of HCWs & & & & & \\
\hline Doctor & 68 & 96 & 32 & 4 & $\mathbf{2 0 0}$ \\
\hline Nurse & 51 & 113 & 73 & 3 & $\mathbf{2 4 0}$ \\
\hline Technician & 48 & 83 & 98 & 11 & $\mathbf{2 4 0}$ \\
\hline Assistant and general staff & 27 & 41 & 30 & 16 & $\mathbf{1 1 4}$ \\
\hline Administration staff & 1 & 7 & 4 & 18 & $\mathbf{3 0}$ \\
\hline Total & $\mathbf{1 9 5}$ & $\mathbf{3 4 0}$ & $\mathbf{2 3 7}$ & $\mathbf{5 2}$ & $\mathbf{8 2 4}$ \\
\hline
\end{tabular}


Table 2 HCWs distribution (\%) according to gender, marital status, education, age and employment duration

\begin{tabular}{|c|c|c|c|}
\hline Variables & Description & No. of total HCWs (\%) & No. of positive HCWs (\%) \\
\hline \multirow[t]{2}{*}{ Gender } & Male & $493(59.8)$ & $21(61.76)$ \\
\hline & Female & $331(40.2)$ & $13(35.29)$ \\
\hline \multirow[t]{2}{*}{ Marital status } & Married & $677(82.2)$ & $25(73.52)$ \\
\hline & Unmarried & $147(17.8)$ & $9(26.47)$ \\
\hline \multirow[t]{2}{*}{ Education } & undergraduate & $572(69.4)$ & $32(94.11)$ \\
\hline & Postgraduate & $252(30.6)$ & $2(5.88)$ \\
\hline \multirow[t]{4}{*}{ Age (years) } & $20-29$ & 195 (23.6) & $4(11.76)$ \\
\hline & $30-39$ & $340(41.3)$ & $10(29.41)$ \\
\hline & $40-49$ & $237(28.8)$ & $17(50)$ \\
\hline & $50-59$ & $52(6.3)$ & $3(8.82)$ \\
\hline \multirow[t]{6}{*}{ Employment Duration(years) } & $1-5 \mathrm{yr}$ & $152(18.44)$ & $4(11.8)$ \\
\hline & $6-10 \mathrm{yr}$ & $181(21.96)$ & $5(14.7)$ \\
\hline & $11-15 \mathrm{yr}$ & $216(26.21)$ & $11(32.4)$ \\
\hline & $16-20 \mathrm{yr}$ & $135(16.38)$ & $7(20.5)$ \\
\hline & $21-25 \mathrm{yr}$ & $91(11.04)$ & $4(11.8)$ \\
\hline & $26-29 \mathrm{yr}$ & $49(5.94)$ & $3(8.8)$ \\
\hline
\end{tabular}

pressure (38.4\%), followed by non-cooperation of patients (30.9\%), inappropriate handling of instruments $(11.7 \%)$, lack of attention $(6.9 \%)$, hurry $(4.4 \%)$, inexperience $(4 \%)$ and others $(3.7 \%)$.

A total of 729 occupational exposures were recorded in $572 \mathrm{HCWs}$ during the previous one year period of their service. Of the $572 \mathrm{HCW}$ sho acquired injures, $273(82.5 \%)$ were female and $299(60.6 \%)$ male. The mean age of these $\mathrm{HCWs}$ was $30 \pm 7.89$ years, with a minimum age of 20 years and maximum of 54 years. When the number of occupation exposure among the HCWs of different occupational group participated were compared, a high percentage of nurses sustained injuries

Table 3 Statistical analysis of HCV positivity in studied population

\begin{tabular}{|c|c|c|c|c|c|}
\hline \multirow[t]{2}{*}{ Variables } & \multicolumn{2}{|c|}{$\begin{array}{c}\text { HCV } \\
\text { Negative }\end{array}$} & \multicolumn{2}{|c|}{$\begin{array}{c}\text { HCV } \\
\text { Positive }\end{array}$} & \multirow[t]{2}{*}{$\begin{array}{l}\text { Chi-square } \\
\text { (yates test }\end{array}$} \\
\hline & $\mathbf{N}$ & $\%$ & $\mathrm{~N}$ & $\%$ & \\
\hline Male & 472 & 59.7 & 21 & 6.17 & $P=1.000$ \\
\hline Female & 318 & 40.3 & 13 & 38.23 & \\
\hline Married & 652 & 82.5 & 25 & 73.53 & $P=0.2654$ \\
\hline Unmarried & 138 & 17.5 & 9 & 26.47 & \\
\hline $\mathrm{H} / \mathrm{O}$ blood transfusion & 20 & 2.53 & 4 & 11.8 & $P=0.0089$ \\
\hline $\mathrm{H} / \mathrm{O}$ dental treatment & 82 & 10.4 & 18 & 52.9 & $P<0.0001$ \\
\hline $\mathrm{H} / \mathrm{O}$ surgery & 27 & 3.41 & 4 & 11.8 & $P=0.0409$ \\
\hline $\mathrm{H} / \mathrm{O}$ hospitalization & 94 & 11.9 & 4 & 11.8 & $P=0.9811$ \\
\hline $\mathrm{H} / \mathrm{O}$ jaundice & 37 & 4.68 & 3 & 8.82 & $P=0.489$ \\
\hline $\mathrm{H} / \mathrm{O}$ intravenous drug user & 1 & 0.13 & 0 & 0 & $P=1.000$ \\
\hline
\end{tabular}

(47.3\%), followed by technicians (31.3\%), doctors $(13.1 \%)$ and assistant staff (8.2\%).

All of HCWs were aware of the importance of screening of HCV. Of the total, only 202 (24.5\%) were aware of their viral status while only six knew of their condition as an HCV carrier and twenty eight HCWs with positive results were considered asymptomatic.

\section{Discusion}

The HCV prevalence studies carried out in our country during past decades had limited geographical scope, different time frames, applied diverse methodologies, and predominantly focused on hospital based studies and high risk population groups. Despite considerable diversities and limitations, these studies reported the high prevalence of $\mathrm{HCV}$, promulgating the high burden this viral hepatitis poses to population's health [12]. In these hospitals setting even though, preventive measures were already inexistence, but they were improved after the identification of hepatitis as serious occupational hazard. Due to absence of good preventive measures in the past e.g. extensive reuse of non-sterilized syringes, fragile health structure, unscreened blood transfusion, use of contaminated razor by barber, general poverty and poor education, a high prevalence rate was demonstrated in general population of Pakistan [6,7,9]. The wealth of evidences showed that all these factors appears to have played the predominant role in occupational transmission of HCV $[6,9]$. Rate of seroprevalence of HCV antibodies in the general population of Pakistan have been reported as $5.31 \%-7.5 \%$ while 4.1 to $36 \%$ reported from various parts of Khyber Pakhtunkhwa Pakistan [6]. 
In this study $4.1 \%$ anti-HCV positivity was recorded. This figure was lower to that reported from Rawalpindi (5.6\% out of 250 ) [13], from Karachi (6\% out of 217 ) [14] and from Abbottabad (5.6\% out of 125) [10]. The difference in low prevalence rate in this study and high prevalence in previously published literatures from diverse regions of Pakistan reflects the variation in the distribution of $\mathrm{HCV}$ between and within different Pakistani geographical areas, actual difference in risk at different hospitals, and the compulsion of mandatory screening of serological status of patients in these hospitals before undergoing invasive procedures (surgery/ dental), which alerts the HCWs to facilitate appropriate planning during treating the infected patients. On the other hand attempts of viral screening of blood donors have markedly reduced the transfusion-related infections rate in patient population [5]. In contrast, current figure was higher than mentioned (1.6\% out of 383 ) from Islamabad [8] which could be due to reason that $41 \%$ of HCWs had service length between 1-5 years. However, methodological differences of sampling strategies and published data of relatively small-scale surveys also contribute to these differences in seroprevalence.

Genotype-3a was the most prevalent genotype in this studied population followed by genotypes $3 \mathrm{~b}, 1 \mathrm{a}$ and mixed infection. It is reported that $75 \%-90 \%$ of $\mathrm{HCV}$ Pakistani patients [9] were harboring genotype 3a, also confirmed [5-7,15,16].

As for demographic data, neither age group nor marital status was responsible for any statistically significant differences between both groups for HCV while significant association was found between duration of employment in a clinical environment, age of HCWs and education of HCWs [8,17-19].

Rampal et al., [20] documented that each year an estimated figure of more than three million HCWs experience an injury with a biological contaminated sharp instrument and these exposures result in about 16,000 infections of $\mathrm{HCV}$. In this study prevalence of injuries is not uniform in different working departments, among the professional groups, the nurses had the increased vulnerability of injury as they spent greater amount of time in administrative therapies and everything concerning direct assistance to patients. Mass of same evidence was shown by various workers [1,21-24]

While laboratory technicians, who manipulate microorganisms in laboratory, which might involves incidences like transferring blood from the syringe to the vial and missing the target, and anesthesia technicians posed a great threat of acquisition of hepatitis, also confirmed by different authors from worldwide [20-24]. Frequency among doctors was relatively low, probably due to benefit sufficiently from preventative measures and preoperative screening of patients for $\mathrm{HCV}$ in studied hospitals before undergoing surgery. Same conclusion also holds true by others $[17,25]$. None of the administrative staff was found with positive result for $\mathrm{HCV}$, which might be due to their not in direct contact with the patients, but still that factor not eliminate the risk of infection due to small sample size studied. HCWs were at high risk of encountering occupational injuries to blood and other infectious body fluid and therefore have more chances to acquire $\mathrm{HCV}$ in their work places. All the HCV positive HCWs at PIMS hospital, Islamabad, had a definite history of needle stick injury except one had history of surgery [8].

This study results showed that although all HCWs were aware about the importance of screening for hepatitis as it made aware of self-care, start therapy and also apply appropriate preventive measure during their provision of services, however there were gaps in their knowledge and practice. The figures in this study were lower than those reported (93.7\%) [8]. In spite of considering important, this approach is flawed for a number factors including ethical, legal, economic, moral, and cultural come into play here. The absence of a prophylactic vaccine from $\mathrm{HCV}$ infection, the logic of this approach would dictate that repeat and continual screening for $\mathrm{HCV}$ is recommended [19]. Another malaise in our health system is the reuse of contaminated needles and equipment in health related procedure. In this study history of dental treatment, history of surgery and blood transfusion has been demonstrated to be responsible as a route of transmission of HCV. This finding verified results of the earlier studies $[6,25,26]$. Current study was in agreement with previous study $[5,6,9,26]$ that the major contributing factors towards increased HCV prevalence include unchecked blood transfusions and reuse of injection syringes in Pakistani population, as several small groups involved in recycling and repacking of used un-sterilized syringes, which were easily available in market at low cost. Screening in the long term, reduce the pool of hepatitis-infected HCWs performing exposure prone procedure, consequently reduce the frequency of $\mathrm{HCW}$ to patient transmission events [10,21].

In Pakistan, sero-frequency figures are significantly higher $(\mathrm{P}<0.0001)$ for $\mathrm{HCV}$ as compared to populations in surrounding countries like India, Nepal, Iran and Afghanistan. On the basis of above unfavorable figure, Pakistan ranked among the top position in prevalence rate in both populations, which is alarming, confirmed by others [5,7]. As persistence of hepatitis infection has grave consequences and no satisfactory treatment is available so far, it will be fast growing gargantuan proportion if special precautions will not take to check its transmission in hospital setting. Therefore the use of preventive precautions is important tools to 
save themselves of this growing menace. The focus was needed on the safety educational training programs to all level of HCWs and it should be emphasized that there is need to maintain utmost care regarding dealing with needles and sharps and caution during the inbetween handling also. Moreover the areas, incidences, trends, activity, procedures and occupational groups that result in a high risk of transmission of hepatitis to HCWs should be identified in a tactful manner, carefully analyzed and will be used to design the preventive strategies for them.

\section{Conclusion}

This study demonstrates that it is necessary to carry out recycling programs addressing issue of universal precautions and proper training of HCWs in the medical field can be pivotal in preventing $\mathrm{HCV}$.

\section{Abbreviations}

HCV: Hepatitis C Virus; HCWs: Health Care Workers.

\section{Author details}

${ }^{1}$ Molecular Parasitology and Virology Laboratory, Department of Zoology, Kohat University Kohat Khyber Pakhtunkhwa, Pakistan. ${ }^{2}$ Department of Zoology, Islamia College Peshawar (Chartered University) Peshawar, Pakistan. ${ }^{3}$ Institution of Biotechnology and Genetic Engineering, KP Agricultural University Peshawar, Pakistan. ${ }^{4}$ Centre for Applied Molecular Biology, Ministry of Science and Technology Lahore, Pakistan. ${ }^{5}$ Institute of Basic Medical Sciences, Khyber Medical University Peshawar, Pakistan.

\section{Authors' contributions}

SK and SA designed and gave a critical view of manuscript writing. SA collected epidemiological data; SNK performed PCR analysis and analyzed the data statistically. SS helped SA in molecular genotyping assays. MB and SS gave critical view of manuscript writing and participated in data analysis. All the authors' read and approved the final manuscript.

\section{Competing interests}

The authors declare that they have no competing interests.

Received: 5 February 2011 Accepted: 8 March 2011 Published: 8 March 2011

\section{References}

1. Sharma R, Rasania SK, Verma A, Saudan : Study of prevalence and response to needle stick injuries among health care workers in a tertiary care hospital in Delhi, India. Indian journal of community medicine 2010, 35(1):74-77.

2. Yazdanpanah Y, De-Carli G, Migueres B, Lot F, Campins M, Colombo C, Thomas T, Deuffic-Burban S, Prevot MH, Domart M, Tarantola A, Abiteboul D, Deny P, Pol S, Desenclos JC, Puro V, Bouvet E: Risk factors for hepatitis $C$ virus transmission to Health Care Workers after occupational exposure: a European case-control study. Rev Epidemiol Sante Publique 2006, 54(1):23-31.

3. Hadadi A, Afhami S, Karbakhsh M, Esmailpour N: Occupational exposure to body fluids among healthcare workers: a report From Iran. Singapore Med J 2008, 49(6):429.

4. Tansley PD, Beresford N, Ladas G, Goldstraw P, Dusmet M: Infection of patients by bloodborne viruses. Br J Surg 2004, 91(4):7.

5. Raja N, Janjua KA: Epidemiology of hepatitis $C$ virus infection in Pakistan. J Microbiol Immunol Infect 2008, 41:4-8.

6. Ali SA, Donahue RMJ, Qureshi $\mathrm{H}$, Vermund $\mathrm{SH}$ : Hepatitis B and hepatitis C in Pakistan: prevalence and risk factors. International J of infectious diseases 2010, 13(1):9-19.
7. Umar M, Ahmad M, Khurram M, Usman S, Arif M, Adam T, Minhas Z, Arif A, Naeem A, Ejaz K, Butt Z, Bilal M: Hepatitis C in Pakistan: A Review of Available Data. Hepat Mon 2010, 10(3):205-214.

8. Hussain S, Patrick NA, Shams R: Hepatitis B and C Prevalence and Prevention Awareness among Health Care Workers in a Tertiary Care Hospital. International Journal of Pathology 2010, 8(1):16-21.

9. Waheed Y, Shafi T, Safi SZ, Qadri I: Hepatitis C virus in Pakistan: A systematic review of prevalence, genotypes and risk factors. World J Gastroenterol 2009, 15(45):5647-5653.

10. Sarwar J, Gul N, Idris M, Farid J, Adeel MY: Seroprevalence of Hepatitis B and Hepatitis C in Health Care Workers in Abbottabad. J Ayub Med Coll Abbottabad 2008, 20(3):27-29.

11. Ohno T, Mizokami M, Wu RR, Saleh MG, Ohba Kl, Orito E, Mukaide M, Williams R, Lau JYN: New Hepatitis C Virus (HCV) Genotyping System that allows for identification of HCV genotypes 1a, 1b, 2a, 2b, 3a, 3b, 4, 5a and 6a. J Clin Microbiol 1997, 35:201-207.

12. Quresh Hi, Bile KM, Jooma R, Alam SE, Afridi HUR: Prevalence of hepatitis $B$ and $C$ viral infections in Pakistan: findings of a national survey appealing for effective prevention and control measures. EMHJ 2010, 16:395-9.

13. Aziz S, Memon A, Tily HI, Rasheed K, Jehangir K, Quraishy MS: Prevalence of HIV, hepatitis B and C amongst health workers of Civil Hospital Karachi. J Pak Med Assoc 2002, 52:92-4.

14. Khurum M: Prevalence of anti-HCV antibodies among health care workers of Rawalpindi and Islamabad. Rawal Med J 2003, 28:7-11.

15. Ahmad NA: study of HCV and its molecular epidemiology in the loca population of Faisalabad region. Phd thesis. Agriculture University, Faisalabad. Pakistan. Pakistan Research Repository; 2004

16. Ahmad N, Asgher M, Shafique M, Qureshi JA: An evidence of high prevalence of Hepatitis C virus in Faisalabad, Pakistan. Saudi Med J 2007, 8(3):390-5.

17. Montella M, Crispo A, Grimaldi M, Ruffolo P, Ronga D, Izzo D, Mastro AA: An assessment of hepatitis $C$ virus infection among health-care workers of the National Cancer Institute of Naples, Southern Italy. The European Journal of Public Health 2005, 15(5):467-469.

18. Ciorlia LAS, Zanetta DMT: Hepatitis C in health care professionals: prevalence and association with risk factors. Rev Saúde Pública 2007, 41(2).

19. Resende VL, Abreu MH, Paiva SM, Teixeira R, Pordeus SA: Factors associated with seroprevalence of hepatitis $C$ among dentists at a large Brazilian city. Virology Journal 2009, 6:228.

20. Rampal L, Zakaria R, Sook LW, Zain AM: Needle Stick and Sharps Injuries and Factors Associated Among Health Care Workers in a Malaysian Hospital. European Journal of Social Sciences 2010, 13(3):354-362.

21. Ciorlia LAS, Zanetta DMT: Hepatitis B in healthcare workers: prevalence, vaccination and relation to occupational factors. Brazilian Journal of Infectious Diseases 2005, 9(5):384-389.

22. Jahan S: Epidemiology of needlestick injuries among health care workers in a secondary care hospital in Saudi Arabia. Annals of Saudi medicine 2005, 25(3):233-8.

23. Singru SA, Banerjee M: Occupational exposure to blood and body fluids among health care workers in a teaching hospital in Mumbai, India. India Journal of community medicine 2008, 1: 26-30.

24. Lachowicz R, Matthews PA: Original Research: The pattern of sharps injury to health care workers at Witbank Hospital SA. Fam Pract 2009, 51(2):148-151.

25. Alam S, Ahmad N, Khan M, Mustafa G, Al Mamun A, Mashud G: Seroprevalence of Hepatitis C Virus Infection among Health Care Workers. J Bangladesh College of Physicians and Surgeons 2007, 25(3):126-129.

26. Ghias M, Pervaiz MK: Identification of epidemiological risk factors for hepatitis c in Punjab, Pakistan. J Ayub Med Coll Abbottabad 2009, 21(2):156-161.

doi:10.1186/1743-422X-8-105

Cite this article as: Khan et al:: Molecular epidemiology of HCV among health care workers of Khyber Pakhtunkhwa. Virology Journal 2011 8:105. 